\title{
The effect of gender and proficiency level on writing strategy use among Iraqi high school students
}

\begin{abstract}
This study aims to 1) explore the extent Iraqi high school students' use of writing strategies; 2) identify the contribution of proficiency level to writing strategy use; and 3) compare male and female students' writing strategy use. This study employed a quantitative approach, whereby a total of 132 high school students were randomly selected from the Karkh'sdistrict of Baghdad to constitute the sample of the study. A 30-item 3-point Likert scale questionnaire on writing strategy use that was adapted from Petrić\&Czárl's (2003) writing strategy questionnaire served as the instrument of the study. The results of the study reveal that the frequency of strategy use was low among the participants. In addition, no significant difference was found between high and low proficiency students'strategy use. Finally, it was found that there is significant difference between female and male students' strategy use. Female students were found to use writing strategies more than males. The paper concludes with a discussion on the implications of the findings.
\end{abstract}

Keyword: Gender; Iraqi EFL learners; Language proficiency; Writing strategy 